\title{
Sintesis Senyawa Mentil Vanilat dari Vanilin dan Aplikasinya sebagai Parfum
}

\author{
Ade Irfan Risnandar ${ }^{*}$, Susy Yunita Prabawati ${ }^{2}$ \\ ${ }^{1}$ Quality Control, PT. de Glow International \\ ${ }^{2}$ Fakultas Sains dan Teknologi, UIN Sunan Kalijaga \\ *AdeirfanRisnandar@gmail.com
}

\begin{abstract}
ABSTRAK
Telah dilakukan sintesis senyawa Mentil Vanilat berbahan dasar vanilin dan aplikasinya sebagai parfum. Sintesis Mentil Vanilat dilakukan melalui oksidasi vanillin menghasilkan asam vanilat dilanjutkan dengan esterifikasi Asam Vanilat menghasilkan senyawa mentil vanilat. Oksidasi Vanilin dilakukan menggunakan reagen Tollens dan esterifikasi Asam Vanilat menggunakan senyawa mentol. Hasil oksidasi senyawa vanilin dilakukan uji titik leleh dan dikarakterisasi menggunakan Fourier Transform Infrared (FTIR). Esterifikasi Asam Vanilat menggunakan mentol dilakukan dengan penambahan reagen tionil klorida $\left(\mathrm{SOCl}_{2}\right)$. Senyawa hasil sintesis dikarakterisasi menggunakan FTIR dan Proton Nuclear Magnetic Resonance $\left({ }^{1} \mathrm{H}-\right.$ NMR) dan dilakukan uji organoleptik. Uji titik leleh Asam Vanilat memberikan hasil sebesar $212^{\circ} \mathrm{C}$ mendekati titik leleh asam vanilat standar yaitu $210^{\circ} \mathrm{C}$. Identifikasi Senyawa asam vanilat dengan FTIR ditunjukkan dengan tidak terlihatnya serapan gugus $\mathrm{C}-\mathrm{H}$ aldehid pada bilangan gelombang dekat $2850 \mathrm{~cm}^{-1}$ dan $2750 \mathrm{~cm}^{-1}$. Hal ini menandakan gugus aldehid dari vanilin telah teroksidasi sempurna. Esterifikasi Asam Vanilat menggunakan mentol dengan penambahan pereaksi $\mathrm{SOCl}_{2}$ menghasilkan reaksi yang irreversible dan diperoleh cairan yang berwarna coklat yang merupakan senyawa ester Mentil Vanilat. Senyawa Mentil Vanilat hasil sintesis diperoleh dengan rendemen $48.05 \%$. Identifikasi dengan FTIR menunjukkan terbentuknya senyawa Mentil Vanilat yaitu adanya serapan gugus $\mathrm{C}-\mathrm{O}$ ester pada bilangan gelombang $1219.01 \mathrm{~cm}-1$ dan $1180.04 \mathrm{~cm}-1$ dengan FTIR, sedangkan dari hasil intepretasi ${ }^{1} \mathrm{H}-$ NMR terlihat serapan pada pergeseran kimia 0.742.16 ppm yang merupakan serapan proton dari gugus mentil yang telah tersubtitusi, berdasarkan hasil identifikasi menggunakan spektrofotometer FTIR dan 1H-NMR yang telah dilakukan, dapat disimpulkan bahwa senyawa Mentil Vanilat telah berhasil disintesis. Sedangkan hasil uji organoleptik menyatakan 95\% responden menyatakan harum, $100 \%$ responden menyatakan produk beraroma tajam, dan $75 \%$ responden menyukai produk senyawa hasil sintesis.
\end{abstract}

Kata kunci: Asam Vanilat, Esterifikasi, $\mathrm{SOCl}_{2}$, Parfum, Vanilin.

\begin{abstract}
Synthesis of menthyl vanilate compound has been carried out and its application as perfume. The synthesis was carried out through oxidation of vanillin using Tollens reagent followed by esterification of vanillic acid with menthol. The result of oxidation process were analyzed for melting point and characterized using FTIR. Esterification of vanillic acid using menthol was carried out by addition of $\mathrm{SOCL}_{2}$ reagent. The synthesized compound was characterized using FTIR and Proton Nuclear Magnetic Resonance $\left({ }^{1} \mathrm{H}-\mathrm{NMR}\right)$ and followed by organoleptic test. Melting point of vanillic acid is $212^{\circ} \mathrm{C}$. Identification of vanillic acid with FTIR is shown that the absorption of C-H aldehyde at wave numbers 2850 and $2750 \mathrm{~cm}^{1}$ is absence indicating that the aldehyde group of vanillin has been oxidized completely.
\end{abstract}


Esterification of Vanillic acid using menthol with the addition of $\mathrm{SOCl}_{2}$ produces an irreversible reaction and obtained a brown liquid which is mentil vanilat ester compound. Synthesis of menthyl vanilate compound was obtained with yield $48.05 \%$. Identification of menthyl vanillate with FTIR showed the absorption of C-O (from Ester) at wave numbers 1219 and $1180 \mathrm{~cm}^{-1}$. Identification with ${ }^{1} \mathrm{H}$ NMR showed the peak at chemical shift $0.742 .16 \mathrm{ppm}$ which is absorption of proton from the substituted menthyl group. Based on the result of identification using FTIR and ${ }^{1} \mathrm{H}$ NMR spectrophotometers can be concluded that menthyl vanillate compound has been successfully synthesized. The result of organoleptic test showed that $95 \%$ of respondents agree that the compound is fragrant, $100 \%$ respondents agree that the the aroma of compound is sharp, and $75 \%$ of respondents like the product of the synthesized compound to be perfume.

Keyword: Vanillic Acid, Esterification, $\mathrm{SOCl}_{2}$, Perfume, Vanillin.

\section{PENDAHULUAN}

Parfum adalah gabungan senyawa kimia yang memberikan aroma wangi. Komponen senyawa parfum dapat dibuat dengan mensintesis senyawa ester. Senyawa ester adalah senyawa yang berbau harum, yang dapat diperoleh dari reaksi alkohol dan asam karboksilat. Bahan dasar pembuatan parfum biasanya berasal dari bahan sintetis dan alami. Namun, dewasa ini bahan dasar sintetis cenderung memberikan efek samping seperti peradangan, pembengkakan sel otak, serta reaktif terhadap pertumbuhan sel. sehingga banyak konsumen maupun produsen yang memilih menggunakan bahan dasar alami. Bahan dasar alami yang digunakan berasal dari tumbuhtumbuhan yang biasanya diekstrak dan kemudian diisolasi.

Indonesia merupakan Negara yang kaya akan tanaman yang memiliki banyak potensi namun belum dimanfaatkan secara maksimal. Salah satu tumbuhan yang memiliki potensi sebagai zat aromatik adalah vanillla (vanilla planifolia A). Vanilla dikenal sebagai tumbuhan penghasil vanilin. Vanilin berbentuk serbuk putih yang menjarum. Secara umum, vanilin digunakan sebagai bahan tambahan pada makanan dan minuman karena vanilin memiliki aroma buah vanilla [1]. Vanilin memiliki nama kimia 4hidroksi-3-metoksi benzaldehida $\left(\mathrm{C}_{8} \mathrm{H}_{8} \mathrm{O}_{3}\right)$ dan termasuk dalam golongan senyawa fenol [2]. Pada penelitian ini, dilakukan sintesis senyawa mentil vanilat, tahap awal pada penelitian ini adalah melakukan oksidasi senyawa vanillin menggunakan oksidator $\mathrm{AgNO}_{3}$, sehingga diperoleh senyawa asam vanilat yang selanjutnya dilakukan reaksi esterifikasi dengan reagen mentol. Senyawa hasil sintesis dilakukan uji organoleptik terhadap sejumlah panelist.

\section{METODOLOGI PENELITIAN Alat dan Bahan}

Peralatan yang digunakan pada penelitian adalah alat gelas, satu set alat refluks, alat penangas es, alat hot plate, alat timbangan digital, alat spektrofotometer Fourier Transform Infra Merah (FTIR, Shimadzu, Prestige 21), alat uji melting point (electrothermal-9100), dan Spektrometer resonansi magnetic inti proton Hidrogen $\left(\mathrm{H}^{1}\right.$ NMR) (399.838 MHz) JEOL menggunakan standar internal TMS dengan pelarut $\mathrm{CDCl}_{3}$.

Bahan-bahan yang digunakan pada penelitian ini memiliki kualitas pro analisis dari Merck. bahan-bahan yang digunakan meliputi perak nitrat $\left(\mathrm{AgNO}_{3}\right)$, natrium hidroksida $(\mathrm{NaOH})$, akuades, vanilin $\left(\mathrm{C}_{8} \mathrm{H}_{8} \mathrm{O}_{3}\right)$, asam sulfat pekat $\left(\mathrm{H}_{2} \mathrm{SO}_{4}\right)$, tionil klorida $\left(\mathrm{SOCl}_{2}\right)$, piridin, mentol, es batu dan natrium sulfat $\left(\mathrm{Na}_{2} \mathrm{SO}_{4}\right)$.

\section{Prosedur}

\section{a. Oksidasi Vanilin}

Larutan 3,37 g $\mathrm{AgNO}_{3} \quad(20 \mathrm{mmol})$ dicampurkan dengan larutan dari 0,93 g $\mathrm{NaOH}$ (23 mmol), kemudian diaduk selama 5 menit. Endapan $\mathrm{Ag}_{2} \mathrm{O}$ yang terbentuk 
disaring lalu dicuci dengan akuades. Oksidasi basah $\mathrm{Ag}_{2} \mathrm{O}$ ditambahkan $40 \mathrm{~mL}$ aquades, 3,93 g (97 mmol) pellet $\mathrm{NaOH}$ sambil diaduk kuat, kemudian temperatur dinaikkan. Ketika temperatur mencapai 55$60^{\circ} \mathrm{C}, 3,04 \mathrm{~g}$ vanilin $(20 \mathrm{mmol})$ dimasukkan dan diaduk kuat selama lebih kurang 10 menit. Setelah itu, campuran disaring dengan kertas saring dan filtratnya diasamkan dengan asam sulfat pekat sampai terbentuk kristal asam vanilat yang tidak larut lagi. Kristal asam vanilat yang terbentuk difiltrasi lalu dicuci dengan akuades. Kristal asam vanilat yang terbentuk selanjutnya diekstraksi cair-cair menggunakan etil asetat dan aquades dengan perbandingan 1:1 (v:v), larutan organik dipisah kemudian dikeringkan sehingga diperoleh asam vanilat yang murni. Kristal asam vanilat yang terbentuk dikumpulkan dan dihitung rendemennya kemudian dilakukan uji titik leleh dan diidentifikasi mengggunakan spektrofotometer FTIR untuk melihat perbedaan dengan senyawa bahan dasarnya.

\section{b. Esterifikasi Asam Vanilat}

Asam vanilat $1,5 \mathrm{~g} \quad(0,0089 \mathrm{~mol})$ ditambahkan ke dalam $2 \mathrm{~mL}(0,02 \mathrm{~mol})$ $\mathrm{SOCl}_{2}$ dalam labu leher tiga kapasitas 250 $\mathrm{mL}$. Campuran direfluks pada suhu $45^{\circ} \mathrm{C}$ selama 1 jam. Kemudian didinginkan dalam penangas es hinggga suhu mencapai $10^{\circ} \mathrm{C}$. Setelah vaniloil klorida mencapai suhu $10^{\circ} \mathrm{C}$, vaniloil klorida dialiri gas $\mathrm{N}_{2}$, kemudian ditambahkan mentol sebanyak $2,78 \mathrm{~g}(0,0178 \mathrm{~mol})$ sedikit demi sedikit melalui corong penambah dan ditambahkan 1 tetes piridin untuk mengikat $\mathrm{HCl}$ sisa reaksi. Campuran direfluks selama 30 menit. Hasil yang diperoleh ditambah dengan $\mathrm{Na}_{2} \mathrm{SO}_{4}$ anhidrat dan kemudian disaring. Filtrat yang didapatkan ditimbang kemudian dihitung rendemennya berdasarkan persamaan (1) dan dianalisis menggunakan FTIR dan 1HNMR.

rendemen $=\frac{\text { berat senyawa hasil sintesis }(\mathrm{gr})}{\text { berat senyawa secarateori }(\mathrm{gr})} \times 100 \%$

\section{c. Uji Organoleptik}

Uji Organoleptik ditujukan untuk menguji senyawa hasil sintesis yang diaplikasikan sebagai parfum. Adapun kriteria yang diuji yaitu keharuman aroma, ketajaman aroma, dan tingkat kesukaan terhadap aroma yang dihasilkan. Uji organoleptik ini menggunakan responden tak terlatih, dengan bahan uji tanpa pembanding. Masing-masing subjek pengujian menggunakan penilaian dengan skala 1-7. Sebanyak 20 orang responden dari berbagai profesi dan prodi mengisi angket yang berisi pendapat.

\section{HASIL DAN PEMBAHASAN}

Oksidasi senyawa vanillin diawali dengan melarutkan $\mathrm{AgNO}_{3}$ ke dalam larutan $\mathrm{NaOH}$ pada suhu ruangan. sehingga menghasilkan endapan $\mathrm{Ag}_{2} \mathrm{O}$ yang berwarna coklat kehitaman serta garam $\mathrm{NaNO}_{3}$ yang larut dalam air. Reaksi yang terjadi seperti pada Persamaan 1.

Pers. 1.

$2 \mathrm{AgNO}_{3(\mathrm{~s})}+2 \mathrm{NaOH}_{(\mathrm{l})} \rightarrow \mathrm{Ag}_{2} \mathrm{O}_{(\mathrm{s})}+\mathrm{H}_{2} \mathrm{O}_{(\mathrm{l})}+$ $\mathrm{NaNO}_{3(\mathrm{~s})}$

Endapan $\mathrm{Ag}_{2} \mathrm{O}$ yang terbentuk selanjutnya dicuci dengan aquades untuk menghilangkan sisa garam, selanjutnya disaring menggunakan kertas saring. Pencucian $\mathrm{Ag}_{2} \mathrm{O}$ yang tidak sempurna memberikan hasil asam vanilat yang tidak sempurna [3]. $\quad \mathrm{Ag}_{2} \mathrm{O}$ yang terbentuk selanjutnya digunakan untuk mengoksidasi gugus aldehid pada senyawa vanilin. Oksidasi gugus aldehid menggunakan Perak(I)Oksida merupakan oksidasi gugus fungsional secara selektif sehingga proses oksidasi yang dilakukan pada suatu senyawa tepat menyerang gugus aldehid saja sehingga reaksi dapat diperkirakan berjalan searah. Senyawa vanilin memiliki gugus fungsi berupa gugus hidroksi, gugus metoksi, gugus benzene dan gugus aldehid sehingga diperlukan senyawa oksidator gugus aldehid yang lebih selektif untuk mengoksidasi agar tidak merusak gugus lain selain aldehid. Metode ini dilakukan dengan 
melarutkan kembali endapan $\mathrm{Ag}_{2} \mathrm{O}$ dengan ditambahkan aquades dan larutan $\mathrm{NaOH}$ berlebih sambil diaduk kuat, kemudian temperatur dinaikkan sampai suhunya mencapai $55^{\circ} \mathrm{C} \quad-60^{\circ} \mathrm{C}$. Ketika suhu mencapai $56^{\circ} \mathrm{C}$, vanilin dimasukkan dan kemudian diaduk kuat selama 10 menit. Pengaturan suhu pada $55^{\circ} \mathrm{C}-60^{\circ} \mathrm{C}$ adalah dikarenakan reaksi oksidasi vanilin menjadi Asam Vanilat akan berlangsung secara optimal pada rentang suhu tersebut. Pada suhu kurang dari $55^{\circ} \mathrm{C}$, reaksi belum berlangsung, sedangkan pada suhu yang lebih tinggi (di atas $60^{\circ} \mathrm{C}$ ) reaksi akan berlangsung terlalu kuat, sehingga dapat menyebabkan perak yang didapat sebagai hasil reduksi $\mathrm{Ag}_{2} \mathrm{O}$ akan teroksidasi kembali [3].

Reaksi antara $\operatorname{Ag}_{2} \mathrm{O}$ dan vanilin berlangsung hingga terjadi perubahan warna endapan $\mathrm{Ag}_{2} \mathrm{O}$ dari coklat kehitaman menjadi abu-abu keperakan karena telah tereduksi menjadi perak (Ag). Endapan perak kemudian difiltrasi dengan menggunakan kertas saring dan filtratnya diasamkan dengan $\mathrm{H}_{2} \mathrm{SO}_{4}$ (asam sulfat) pekat sedikit demi sedikit menggunakan pipet tetes. Filtrat yang terbentuk berwarna kuning kehijauan. Penggunaan asam sulfat bertujuan untuk menghidrolisis garamgaram yang terbentuk akibat penggunaan basa $\mathrm{NaOH}$ berlebih. $\mathrm{NaOH}$ bereaksi dengan vanilin membentuk natrium vanilat serta senyawa fenolik pada struktur vanilin membentuk senyawa garamnya [4]. Dengan hidrolisis menggunakan asam sulfat, maka Asam Vanilat dapat terbentuk. Reaksi oksidasi vanillin disajikan pada Gambar.1.

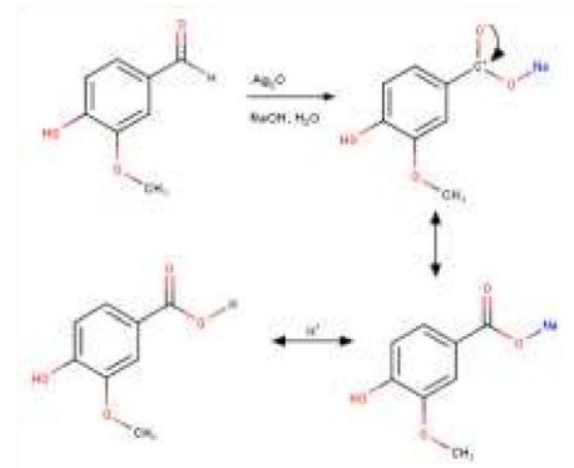

Gambar.1. Mekanisme reaksi oksidasi vanillin.
Saat kesetimbangan tercapai, penambahan asam sulfat menghasilkan endapan berwarna putih krem yang tidak dapat larut lagi. Endapan tersebut merupakan endapan Asam Vanilat. Endapan yang terbentuk kemudian dimurnikan dengan metode ekstraksi. Metode ekstraksi dilakukan dengan mengumpulkan endapan Asam Vanilat yang terbentuk kemudian dilarutkan dengan etil asetat dan dimasukkan kedalam corong pisah lalu ditambah dengan aquades dengan perbandingan 1:1 (v/v). Kedua larutan digojog selama beberapa menit kemudian fasa organik dipisahkan dan pelarutnya diuapkan hingga terbentuk padatan berwarna putih gading yang merupakan Asam Vanilat yang murni.

Uji titik leleh asam vanilat diperoleh sebesar $212^{\circ} \mathrm{C}$ sedangkan senyawa vanilin $82^{\circ} \mathrm{C}$. Perbedaan titik leleh yang signifikan ini menunjukkan bahwa produk yang diperoleh merupakan senyawa yang berbeda dari reaktan. Sehingga dapat disimpulkan bahwa produk sudah terbentuk. Senyawa Asam Vanilat yang diperoleh juga dibandingkan dengan Asam Vanilat standar, dimana Asam Vanilat standar memiliki titik leleh $210^{\circ} \mathrm{C}$. Hal tersebut membuktikan bahwa asam vanilat yang diperoleh cukup murni karena memiliki perbedaan titik leleh yang tidak terlalu jauh dengan Asam Vanilat standarnya. Hasil identifikasi dengan uji titik leleh dilanjutkan dengan karakterisasi menggunakan spektrofotometer Fourier Transform InfraRed (FTIR) untuk mengidentifikasi keberadaan gugus fungsi yaitu gugus karboksilat yang terdapat dalam senyawa Asam Vanilat dan dibandingkan dengan bahan dasarnya yaitu vanilin. Perbandingan spektra FTIR senyawa vanillin dan asam vanilat disajikan pada Gambar.2. 


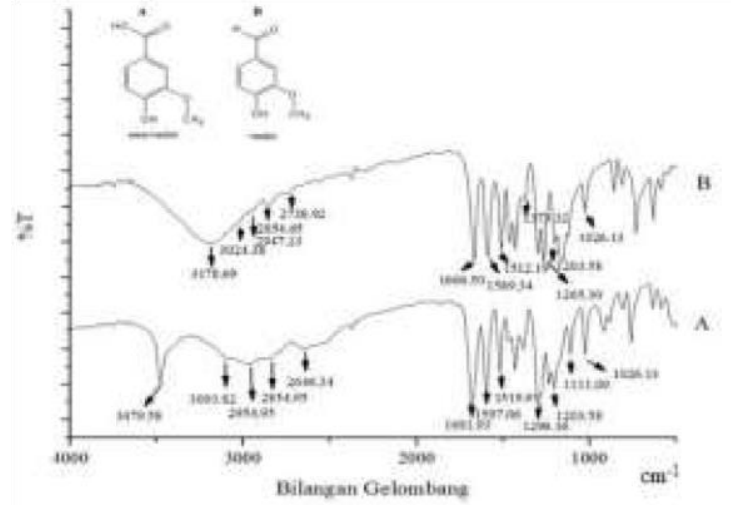

Gambar.2. perbandingan spektra FTIR senyawa vanillin dan asam vanilat

Tabel.1 perbandingan bilangan gelombang gugus fungsi pada senyawa vanillin dan asam vanilat.

\begin{tabular}{|c|c|c|c|}
\hline \multirow{2}{*}{ No } & \multicolumn{2}{|c|}{ Bilangan Gelombang } & \multirow{2}{*}{} \\
\cline { 2 - 3 } & $\begin{array}{c}\text { Asam Vanilat } \\
\left(\mathrm{cm}^{-1}\right)\end{array}$ & $\begin{array}{c}\text { Vanilin } \\
\left(\mathrm{cm}^{-1}\right)\end{array}$ & $\begin{array}{c}\text { Gugus } \\
\text { Fungsi }\end{array}$ \\
\hline 1 & - & $\begin{array}{c}2738 ; \\
2854\end{array}$ & $\begin{array}{c}\text { C-H } \\
\text { (aldehid) }\end{array}$ \\
\hline 2 & 3479 & 3178 & $-\mathrm{OH}$ \\
\hline 3 & 1681 & $1666 ;$ & $\mathrm{C}=\mathrm{O}$ \\
& & 1589 & \\
\hline 4 & 1381 & 1373 & $\begin{array}{c}\text { C-O-C } \\
(\text { eter })\end{array}$ \\
\hline
\end{tabular}

Berdasarkan Table.1 yang telah disajikan, dapat disimpulkan bahwa senyawa vanilin dan asam vanilat mengalami pergeseran pada bilangan gelombang tertentu yang mengindikasikan senyawa yang diperoleh sudah teroksidasi menjadi senyawa Asam Vanilat. Hal tersebut dibuktikan pada pergeseran bilangan gelombang $2854 \mathrm{~cm}^{-1}$ dan $2738 \mathrm{~cm}$ ${ }^{-1}$ dari spektrum vanilin yang merupakan perkiraan untuk $\mathrm{C}-\mathrm{H}$ aldehid sudah tidak muncul lagi pada spektrum Asam Vanilat.

\section{B. Hasil Esterifikasi Asam Vanilat}

Sintesis senyawa ester Mentil Vanilat dilakukan dengan cara esterifikasi pada senyawa turunan asam karboksilat yaitu Asam Vanilat. Sintesis senyawa ester Mentil Vanilat diawali dengan mereaksikan Asam Vanilat dengan tionil klorida $\left(\mathrm{SOCl}_{2}\right)$ kemudian direfluks pada suhu $45^{\circ} \mathrm{C}$ selama 1 jam. Penambahan $\mathrm{SOCl}_{2}$ berfungsi untuk membentuk halida asam yaitu vaniloil klorida. Pembentukan vaniloil klorida bertujuan untuk meningkatkan keasaman sehingga mudah bereaksi dengan senyawa alkohol yaitu mentol dan diperoleh reaksi yang irreversible sehingga diperoleh senyawa produk yang murni dengan rendemen yang optimum. Reaksi pembentukan halida asam ini merupakan reaksi yang eksotermis sehingga terjadi kenaikan suhu dari $45^{\circ} \mathrm{C}$ menjadi $52^{\circ} \mathrm{C}$ dan terbentuknya vaniloil klorida ditandai dengan larutnya Asam Vanilat dalam $\mathrm{SOCl}_{2}$ serta terbentuknya warna larutan kuning.

Setelah proses refluks selesai, vaniloil klorida yang terbentuk dialiri gas $\mathrm{N}_{2}$ untuk menghilangkan uap air yang mungkin masuk melalui udara. Vaniloil klorida memiliki gugus pergi yang baik, mudah diserang air. Dengan adanya air vaniloil klorida akan mudah kembali menjadi asam vanilat. Reaksi pembentukan vaniloil klorida disajikan pada Gambar.3.

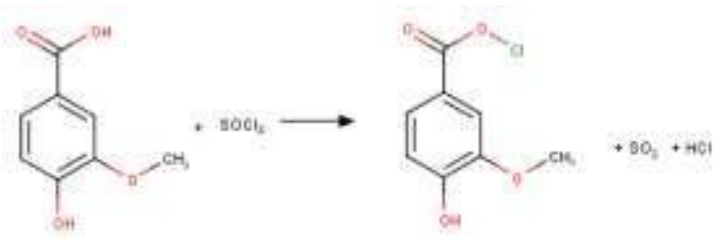

Gambar.3. Reaksi pembentukan vaniloil klorida.

Pembentukan senyawa Mentil Vanilat dilakukan dengan mereaksikan antara vaniloil klorida, mentol, dan piridin dengan proses refluks. Proses ini berlangsung selama 30 menit tanpa adanya pemanasan. Mentol berfungsi sebagai pereaksi untuk membentuk senyawa ester yaitu Mentil Vanilat, sedangkan piridin berfungsi untuk mengikat ion klor yang tersisa selama reaksi sehingga terbentuk garam piridinium klorida yang mudah terpisah oleh Mentil Vanilat yang diinginkan. Hasil refluks yang diperoleh selanjutnya ditambah dengan $\mathrm{Na}_{2} \mathrm{SO}_{4}$ anhidrat untuk mengikat pengotor yang bersifat polar sehingga diperoleh senyawa Mentil Vanilat yang murni dengan berat 1,31 gram. Reaksi pembentukan 
senyawa Mentil Vanilat dapat dilihat pada Gambar.4
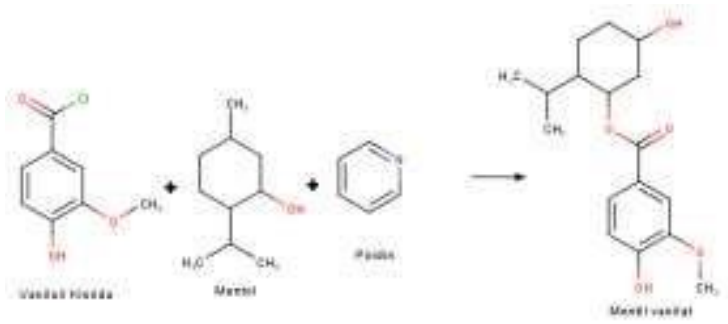

Gambar.4. Reaksi pembentukan senyawa Mentil vanilat.

Senyawa mentil vanilat yang dihasilkan berupa cairan berwarna coklat dan berbau harum dengan rendemen sebesar $48.05 \%$. Analisis menggunakan FTIR menunjukkan terdapat serapan kuat dan lebar pada bilangan gelombang $3340.71 \mathrm{~cm}-1$, hal tersebut menandakan bahwa masih terdapat gugus hidroksi fenolik yang tidak terikat dengan senyawa apapun. Hal ini juga membuktikan bahwa senyawa mentol yang ditambahkan dengan Asam Vanilat tidak menyerang gugus hidroksi fenolik. Serapan pada bilangan gelombang 2924; $2870 \mathrm{~cm}-1$ merupakan serapan gugus $\mathrm{C}(\mathrm{sp} 3)-\mathrm{H}$, kemudian pada bilangan gelombang 1681 cm-1 terdapat serapan gugus $\mathrm{C}=\mathrm{O}$ karbonil yang menunjukkan senyawa Mentil Vanilat. Hal ini didukung dan diperkuat dengan munculnya serapan pada bilangan gelombang $1219 \mathrm{~cm}^{-1}$ dan $1180 \mathrm{~cm}^{-1}$ yang merupakan $\mathrm{C}-\mathrm{O}$ ester dengan hilangnya serapan $-\mathrm{OH}$.

Hasil spektrum FTIR Mentil Vanilat yang diperoleh selanjutnya dibandingkan dengan senyawa bahan dasarnya yaitu Asam Vanilat. Spektra FTIR perbandingan senyawa asam vanilat dan mentil vanilat disajikan pada Gambar 5.

Senyawa Mentil Vanilat dengan senyawa Asam Vanilat memiliki perbedaan yang sangat jelas. Serapan -OH fenolik pada senyawa Mentil Vanilat memiliki peak yang lebih lebar dibanding dengan senyawa Asam Vanilat yang memiliki peak yang runcing, kemudian serapan gugus hidroksi fenolik pada senyawa Mentil Vanilat memiliki bilangan gelombang yang lebih kecil dibanding dengan serapan gugus hidroksi fenolik pada senyawa Asam Vanilat yaitu pada $3340 \mathrm{~cm}^{-1}$ sedangkan Asam Vanilat pada $3479 \mathrm{~cm}^{-1}$. Perbedaan ini mengindikasikan bahwa gugus hidroksi fenolik yang terikat secara para telah mengalami reaksi esterifikasi. Hal ini didukung dan diperkuat dengan adanya serapan pada bilangan gelombang $1219 \mathrm{~cm}^{-}$ ${ }^{1}$ dan $1180 \mathrm{~cm}^{-1}$ yang merupakan C-O ester dengan hilangnya serapan $-\mathrm{OH}$ dari senyawa Mentil Vanilat. Selain itu, pada spektrum senyawa Mentil Vanilat, terdapat serapan tajam pada bilangan gelombang 2924; $2870 \mathrm{~cm}^{-1}$ yang menunjukkan serapan dari $\mathrm{C}(\mathrm{sp} 3)-\mathrm{H}$ dari gugus mentil pada senyawa Mentil Vanilat. Serapan tersebut membuktikan bahwa gugus mentil telah tersubtitusi ke dalam senyawa Asam Vanilat.

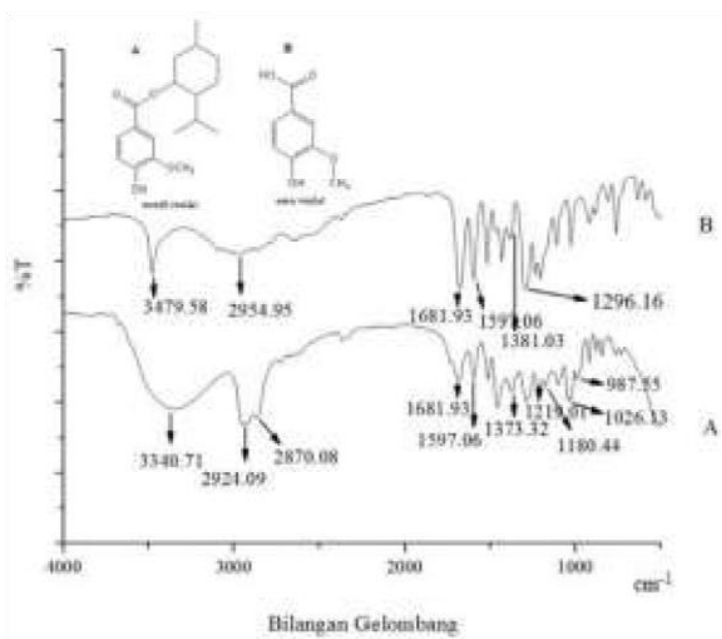

Gambar.5. Perbandingan Spektra FTIR senyawa hasil sintesis dan reaktannya

Secara umum, dapat disimpulkan bahwa senyawa produk hasil sintesis telah mengalami reaksi esterifikasi menjadi senyawa Mentil Vanilat dan produk yang didapatkan sudah bukan lagi senyawa prekursornya. Identifikasi senyawa produk selanjutnya dilakukan dengan instrumen 1H-NMR untuk mengetahui jumlah proton yang terdapat pada lingkungan kimia yang ada pada senyawa produk.

Senyawa hasil sintesis dianalisis menggunakan 1H-NMR $399.838 \mathrm{MHz}$ pada suhu $25^{\circ} \mathrm{C}$ dengan pelarut $\mathrm{CDCl} 3$. Spektra 1H-NMR dari produk hasil sintesis menunjukkan adanya empat lingkungan yang berbeda. Keempat lingkungan tersebut 
masing-masing berada pada pergeseran kimia 0.74-2.16; 3.92; 7.53 - 6.89; dan 4.88 ppm. Spektrum 1H-NMR dari senyawa produk hasil sintesis dapat dilihat pada Gambar 6.

Puncak yang muncul pada pergeseran 0.74-2.16 ppm menunjukkan pergeseran kimia yang terjadi pada senyawa hidrokarbon jenuh (gugus mentil yang tersubtitusi). Serapan hidrogen pada gugus alkana (hidrokarbon jenuh atau alifatik) terdapat pada pergeseran 0.70-1.70 ppm [6],

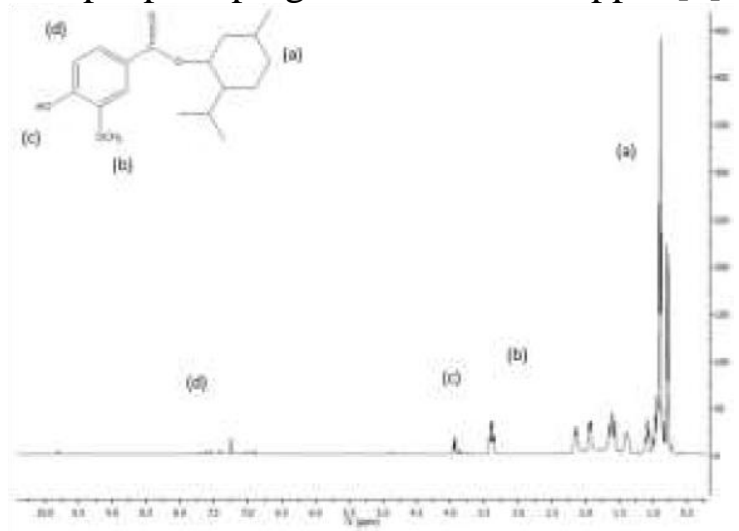

Gambar.6. spektra ${ }^{1} \mathrm{H}$ NMR senyawa mentil vanilat

pada penelitian ini, gugus metana merupakan hidrogen yang lebih terlindungi dan memiliki pergeseran kimia pada $0.701 .30 \mathrm{ppm}$. Pada penelitian ini, senyawa produk yang dihasilkan adalah mentil vanilat. Gugus mentil yang terdapat dalam senyawa produk merupakan senyawa hidrokarbon siklik jenuh sehingga pergeseran pada bilangan gelombang tersebut dapat diasumsikan sebagai puncak pergeseran untuk senyawa mentil. Puncak yang muncul pada pergeseran 0.74-1.08 ppm menunjukkan jumlah proton pada siklo heksana. Puncak multiplet yang ditunjukkan pada spektrum disebabkan oleh pengaruh proton tetangga yang mempengaruhi penyerapan proton inti sehingga diperoleh kenampakan multiplet pada gugus siklo heksana.

Puncak yang muncul pada pergeseran $3.92 \mathrm{ppm}$ merupakan pergeseran pada gugus metoksi dari senyawa vanilin. Proton dari metoksi lebih tidak terlindungi dari proton pada siklo metana. Hal tersebut disebabkan karena proton metoksi terikat pada gugus oksigen yang terikat pada karbon benzen, menyebabkan proton yng terikat pada atom oksigen menjadi lebih tidak terlindungi sehingga proton dari metoksi muncul pada pergeseran yang lebih tinggi yaitu $3.92 \mathrm{ppm}$. Berdasarkan data tersebut [6] juga telah melakukan penelitian sintesis senyawa asetil vanilat, gugus metoksi dari senyawa vanilat pada penelitian tersebut muncul pada pegeseran 3.91 ppm. Pergeseran kimia dari kedua gugus tersebut sangat signifikan sehingga dapat diasumsikan bahwa puncak yang muncul pada pegeseran $3.92 \mathrm{ppm}$ merupakan puncak dari gugus metoksi.

Puncak yang muncul pada pergeseran 6.89-7.59 ppm merupakan puncak dari proton benzen yang terdapat pada senyawa vanilat. Senyawa aromatik memiliki dua tipe penyerapan yaitu penyerapaan pada gugus proton yang terikat dalam cincin benzen dan penyerapan pada gugus benzylic hydrogen [5]. Kedua tipe hidrogen tersebut dikenai pengaruh anisotropi dari cincin benzen sehingga proton dari kedua tipe penyerapan menjadi tak terlindungi. Serapan pergeseran kimia pada proton yang terikat dengan cincin benzen adalah 6.50$8.00 \mathrm{ppm}$ sedangkan serapan pada proton dari benzil hidrogen adalah $2.302 .70 \mathrm{ppm}$.

Puncak yang muncul pada pergeseran kimia $4.88 \mathrm{ppm}$ menunjukkan pergeseran serapan proton pada gugus hidroksi dari senyawa vanilat. Berdasarkan tabel approksimasi rentang pergeseran kimia untuk proton dari senyawa fenol berada pada rentang 4.00-7.00 ppm [5]. Sehingga dapat diasumsikan bahwa serapan pada 4.88 ppm merupakan serapan proton dari gugus hidroksi yang terikat dengan senyawa vanilat. Berdasarkan hasil analisis ${ }^{1} \mathrm{H}-\mathrm{NMR}$ dan FTIR yang telah dilakukan, dapat disimpulkan bahwa senyawa parfum Mentil Vanilat telah berhasil disintesis. Hal tersebut dibuktikan dengan tidak terdeteksinya gugus asam karboksilat pada spektra FTIR Mentil Vanilat dan diperkuat dengan munculnya gugus mentil yang telah disubtitusikan ke dalam gugus Asam Vanilat pada spektra 1H-NMR. 


\section{Uji Organoleptik}

Produk senyawa sisa hasil karakterisasi FTIR dan ${ }^{1} \mathrm{H}$-NMR selanjutnya dilakukan uji organoleptik. Uji Organoleptik merupakan suatu uji dengan memanfaatkan panca indera manusia untuk mengamati tekstur, warna, bentuk, aroma, dan rasa. Selain itu, uji organoleptik juga meliputi uji kesukaan dimana uji kesukaan ini termasuk dalam uji hedonik. Uji hedonik digunakan untuk mengukur sikap subjektif responden berdasarkan sifat-sifat organoleptik dimana responden dimintakan tanggapan pribadinya tentang kesukaan atau sebaliknya (ketidaksukaan) [8]. Pada penelitian ini, uji organoleptik yang dilakukan dibatasi yaitu meliputi keharuman aroma, ketajaman aroma dan tingkat kesukaan seperti yang dilakukan oleh winarto (2012)[8]. Uji organoleptik ini menggunakan responden tak terlatih, dengan bahan uji tanpa pembanding. Masing-masing subjek pengujian menggunakan skala 1-7. Sebanyak 20 orang responden dari berbagai macam profesi dan prodi mengisi angket yang berisi pendapat. Dari angket tersebut didapatkan data sebagai berikut:

\section{Tingkat keharuman}

Tabel.2 Tingkat keharuman responden

\begin{tabular}{|c|c|c|c|}
\hline \multirow[b]{2}{*}{ No } & \multirow[b]{2}{*}{$\begin{array}{c}\text { Tingkat } \\
\text { keharuman }\end{array}$} & \\
\hline & & Skala & Total \\
\hline 1 & $\begin{array}{l}\text { Amat sangat } \\
\text { harum }\end{array}$ & 7 & 0 \\
\hline 2 & Sangat harum & 6 & 2 \\
\hline 3 & Harum & 5 & 15 \\
\hline 4 & Agak harum & 4 & 2 \\
\hline 5 & Agak tidak harum & 3 & 0 \\
\hline 6 & Tidak harum & 2 & 1 \\
\hline 7 & Sangat tidak harum & 1 & 0 \\
\hline & Total responden & & 20 \\
\hline
\end{tabular}

Berdasarkan Tabel.2., sebanyak 15 orang atau $75 \%$ dari 20 responden menyatakan bahwa produk memiliki tingkat keharuman "harum". Sebanyak 2 orang atau $10 \%$ dari total responden menyatakan tingkat keharuman "sangat harum", kemudian 2 orang atau $10 \%$ dari total responden menyatakan tingkat keharuman "agak harum", dan sebanyak 1 orang atau $5 \%$ dari total responden menyatakan tingkat keharuman "tidak harum". Dari hasil tersebut dapat disimpulkan sebanyak 19 orang $(95 \%)$ dari total responden menunjukkan tanggapan positif mengenai keharuman produk.

\section{Tingkat ketajaman aroma}

Tabel.3 Tingkat ketajaman aroma responden

\begin{tabular}{llll}
\hline No & $\begin{array}{l}\text { Tingkat } \\
\text { ketajaman aroma }\end{array}$ & Skala & Total \\
\hline 1 & Amat sangat tajam & 7 & 0 \\
2 & Sangat tajam & 6 & 7 \\
3 & Tajam & 5 & 7 \\
4 & Agak tajam & 4 & 6 \\
5 & Agak tidak tajam & 3 & 0 \\
6 & Tidak tajam & 2 & 0 \\
$\underline{7}$ & $\frac{\text { Sangat tidak tajam }}{\text { Total responden }}$ & 1 & 0 \\
\cline { 3 - 4 } & \multicolumn{2}{c}{ Total } & 20 \\
\hline
\end{tabular}

Berdasarkan Tabel.3., jumlah responden yang menyatakan produk parfum memiliki aroma yang tajam adalah sebanyak 7 orang ( $35 \%$ dari total responden) dan menyatakan bahwa produk parfum memiliki aroma sangat tajam sebanyak 7 orang $(35 \%)$. Sedangkan responden yang menyatakan produk parfum memiliki aroma agak tajam adalah sebanyak 6 orang (30\% dari total responden).

\section{Tingkat Kesukaan}

Sebanyak 5 orang atau $25 \%$ dari total responden menyatakan bahwa produk yang dihasilkan memiliki tingkat kesukaan "suka dan agak suka". Kemudian sebanyak 4 orang atau $20 \%$ dari total responden menyatakan bahwa produk yang dihasilkan memiliki tingkat kesukaan "sangat suka dan agak tidak suka", dan sebanyak 1 orang atau 5\% dari total responden menyatakan bahwa produk yang dihasilkan memiliki tingkat kesukaan "amat sangat suka dan tidak suka". Dengan demikian, dapat disimpulkan sebanyak 15 orang (75\%) dari total 
responden menyatakan suka terhadap aroma parfum dari senyawa produk hasil sintesis. Tingkat kesukaan responden dirangkum pada

Tabel.4. Tingkat kesukaan responden

\begin{tabular}{llll}
\hline No & Tingkat kesukaan & Skala & Total \\
\hline 1 & Amat sangat suka & 7 & 1 \\
2 & Sangat suka & 6 & 4 \\
3 & Suka & 5 & 5 \\
4 & Agak suka & 4 & 5 \\
5 & Agak tidak suka & 3 & 4 \\
6 & Tidak suka & 2 & 1 \\
7 & Sangat tidak suka & 1 & 0 \\
& Total responden & & 20 \\
\hline
\end{tabular}

Secara umum, uji organoleptik yang dilakukan terhadap produk hasil sintesis mendapat tanggapan yang positif, namun dari tingkat kesukaan responden hanya menyukai senyawa produk bukan sebagai parfum badan melainkan sebagai parfum aroma terapi. Hal ini dikarenakan bau yang dihasilkan pada senyawa produk hasil sintesis memiliki bau khas mint selain dari bau vanilla.

\section{KESIMPULAN}

Produk senyawa Mentil Vanilat dapat terbentuk dengan mereaksikan senyawa asam vanilat dengan tionil klorida sehingga diperoleh senyawa vaniloil klorida yang kemudian direaksikan dengan mentol dan diperoleh senyawa Mentil Vanilat. Pengaruh penambahan pereaksi $\mathrm{SOCl}_{2}$ dalam penelitian ini adalah agar reaksi berjalan searah (Irreversible) sehingga tidak terdapat reaksi balik (terbentuk kembali senyawa Asam Vanilat dan mentol), hal tersebut dibuktikan dengan hasil identifikasi senyawa menggunakan FTIR dan ${ }_{1} \mathrm{H}-\mathrm{NMR}$, sehingga produk yang dihasilkan menjadi lebih optimum dengan rendemen sebesar $48.05 \%$. Tanggapan responden terhadap produk yang dihasilkan meliputi: 95\% dari 20 responden menyatakan bahwa produk memiliki ringkat keharuman: harum., 100\% dari 20 responden menyatakan aroma produk yang dihasilkan cenderung tajam., dan $75 \%$ dari 20 responden menyatakan suka terhadap produk yang dihasilkan.

\section{DAFTAR PUSTAKA}

[1] Shyamala B.N., Naidu, M., Sulochannama, G.S.Srinivas.P. 2007. Studies on the antioxidant activities of natural vanilla extract and its constituent compounds through in vitro models. Journal Agricultural and Food Chemistry. Vol 55. 77387743.

[2] Prabawati.S.Y., Setiawan A.F., dan Agustina A.F., 2012, Sintesis Senyawa 1,4-bis[(2-hidroksi-3metoksi-5formaldehid-fenil)metilpiperazin dari bahan dasar vanillin dan uji aktivitasnya sebagai zat antioksidan. Jurnal Kaunia. Vol.8. No.1. 30-43.

[3] Hawa Siti.2007. Studi Sintesis Ester Sukrovanilat dari Sukrosa dan Vanillin yang telah dioksidasi (asam vanilat). Skripsi. FMIPA UI. Depok

[4] Fitrianti Eka. 2008. Sintesis Ester Fruktovanilat dari Fruktosa dan Asam Vanilat Menggunakan Metode Gelombang Mikro Serta Uji Aktivitas Antioksidan. Repository Skripsi. FMIPA UI. Depok

[5] Vyvyan.R.J. Pavia.L., Donald, Lampman.M., Kriz S. George. 2009. Introduction to Spectroscopy Fourth Edition. USA. US Copy Rights Act. [6] Iskandar D. 2015. Sintesis Asetil Vanilat Sebagai Komponen Analgetik. Skripsi. Saintek UIN Sunan Kalijaga. Yogyakarta.

[6] Wagiyono. 2003. Menguji

Kesukaan Secara Organoleptik. Artikel Proyek Pengembangan

Kurikulum. Departemen Pendidikan Nasional

[7] Winarto D., Hanafi R. W., Hikmatiyar H., dan Budimarwanti C. 2012. Sintesis Benzil Asetat Sebagai Bahan Pembuatan Parfum. Jurdik Kimia. Universitas Negeri Yogyakarta 